\title{
Correspondence
}

\section{BIS et pneumencéphale}

La position assise en neurochirurgie expose au risque de survenue de plusieurs complications dont l'embolie gazeuse et le pneumencéphale. Leur diagnostic repose sur l'imagerie tomodensitométrique ou par résonance magnétique réalisée au décours d'un retard de réveil. La surveillance per opératoire comporte habituellement : électrocardioscope, oxymètre, capnogramme, mesure invasive de la pression artérielle, doppler œsophagien, et cathétérisme droit. ${ }^{1}$ Récemment, la mesure de la profondeur de l'anesthésie par analyse bispectrale (BIS) a été introduite. ${ }^{2}$

Nous rapportons le cas d'un patient de 68 ans aux antécédents d'accident ischémique transitoire opéré d'un épendymome du 4ème ventricule. L'anesthésie générale a été obtenue par l'association propofolrémifentanyl.

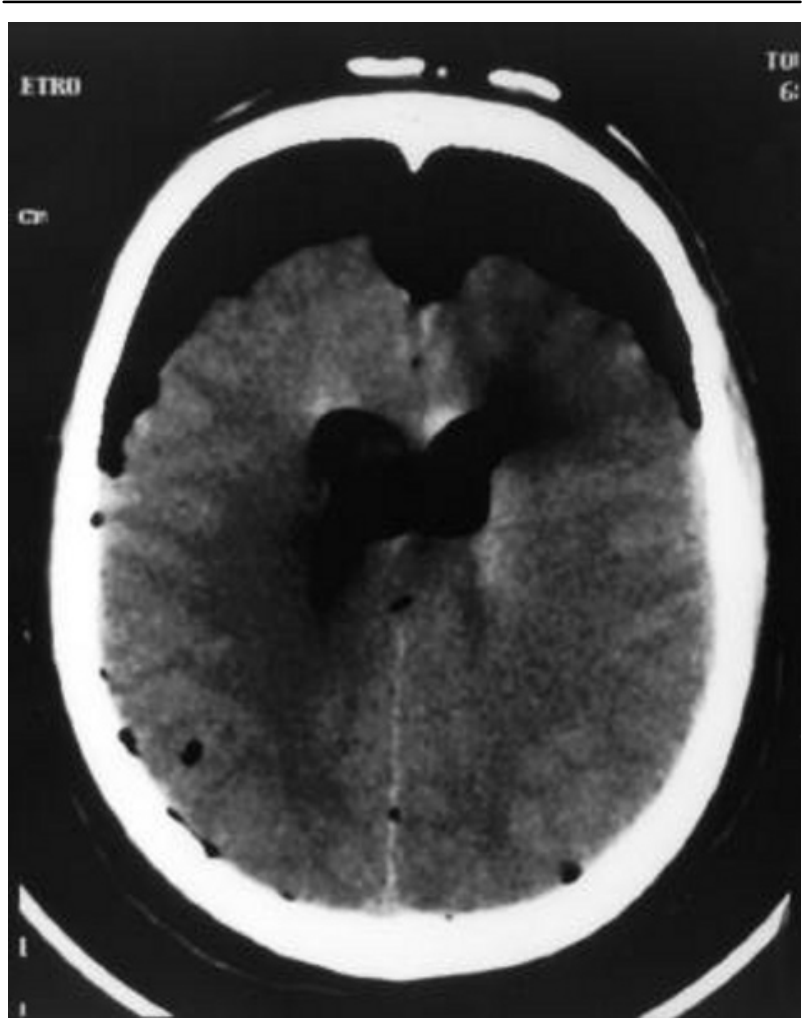

FIGURE Coupe scannographique montrant un volumineux pneumencéphale frontal
Pendant toute l'intervention aucune modification des paramètres de surveillance pouvant faire évoquer la survenue d'une complication n'a été notée. Le BIS $^{\text {TM }}$ (A-1000 Aspect ${ }^{\circledR}$ Medical Systems, Natick, MA) est resté entre 40 et $60 \%$. Compte tenu de ces éléments, et du type d'anesthésie, un réveil sur table a été envisagé. Dès la remise en décubitus dorsal, le BIS $^{\mathrm{TM}}$ est devenu inopérant (indice de qualité à $0 \%$ ) alors que les électrodes étaient toujours en place. Un réveil de mauvaise qualité a conduit à la réalisation d'un examen tomodensitométrique. Celui-ci a révélé un volumineux pneumencéphale frontal (Figure) expliquant l'absence de lecture par le BIS ${ }^{\mathrm{TM}}$.

Le BIS $^{\mathrm{TM}}$ est un moniteur de la profondeur d'anesthésie mais une anomalie de lecture doit, jusqu'à preuve du contraire, faire rechercher un événement pathologique en l'absence de dysfonctionnement de l'appareil.

\section{S. Mérat MD \\ J.-P. Lévecque MD \\ Y. Le Gulluche MD \\ Paris, France}

\section{References}

1 Porter JM, Pidgeon C, Cunningham AJ. The sitting position in neurosurgery: a critical appraisal. $\mathrm{Br} \mathrm{J}$ Anaesth 1999; 82: 117-28.

2 Smith WD, Dutton RC, Smith NT. Measuring the performance of anesthetic depth indicators. Anesthesiology 1996; 84: 38-51.

\section{Arrhythmias during spinal anesthesia for Cesarean section - does high spinal block correlate?}

To the Editor:

The prospective study of Shen and colleagues ${ }^{1}$ is important in alarming us of the higher incidence of arrhythmias than expected during spinal anesthesia, especially for Cesarean section procedures. Their results revealed only increasing age correlated significantly with the incidence of potentially dangerous arrythmias. The authors suggested four mechanisms to explain the high incidence of intraoperative arrhythmias, including blockade of cardiac sympathetic stimu- 
lation or increase of vagal tone. The procedure, i.e., Cesarean section itself requires relatively high sensory block up to T4. ${ }^{2}$ As the authors mentioned, sympathetic blockade might be two segments higher than the sensory block. If the spinal block is higher than $\mathrm{T}_{4}$ level, the chance of thoracic and even cervical ganglia blockade, suffocation leading to hypoxemia and hypercarbia, and the use of drugs which could provoke arrhythmias will be increased. Unfortunately, however, I could not find any comment about the correlation between the incidence of arrhythmias and (1) the level of spinal blockade, (2) frequency and dosage of drugs given, or (3) incidence of subjective and/or objective difficulty in breathing, all of which seems to be the important factors for arrhythmias in high level spinal anesthesia. Further analysis might give us more information from your precious study.

Sangmin M. Lee MD

Seoul, Korea.

\section{References}

1 Shen C-L, Ho $\Upsilon$ - , Hung $\Upsilon$-C, Chen P-L. Arrhythmias during spinal anesthesia for Cesarean section. Can J Anaesth 2000; 47: 393-7.

2 De Simone CA, Leighton BL, Norris MC. Spinal anesthesia for Cesarean delivery. A comparison of two doses of hyperbaric bupivacaine. Reg Anesth 1995; 20: 90-4.

\section{REPLY:}

We appreciate the thoughts of $\mathrm{Dr}$. Lee in our recent report. In fact, we are also interested in the correlation between the arrhythmias and block height, pharmacological intervention, patient symptoms or surgical stimulation. However, the pathogenesis of arrhythmias during spinal anesthesia is complicated. Even the sympathovagal changes induced by spinal anesthesia remain controversial. ${ }^{1,2}$ Our case numbers weretoo small for a meaningful comparison. We only tried to identify parturients at high risk of arrhythmias during spinal anesthesia, so "preanesthetic" risk factors, such as age, body height and weight, were studied.

On the other hand, high spinal block occurred in nearly all of our patients $\left(95.3 \%\right.$ above $\left.T_{6}\right)$. Additionally, there is no uniform definition of high spinal anesthesia. Peak block height greater than or equal to $T_{4} T_{5}$ or $T_{6}$ has been used to be the criteria of high spinal anesthesia. 3,4,5 Therefore, it seems to be inappropriate to analyze the correlation between the arrhythmias and high spinal block in our study.

Chih-Long Shen MD

Taiwan
References

1 Introna R, Yodlowski E, Pruett J, Montano N, Porta A, Crumrine R. Sympathovagal effects of spinal anesthesia assessed by heart rate variability analysis. Anesth Analg 1995; 80: 315-21.

2 Kawamoto M, Tanaka N, Takasaki M Power spectral analysis of heart rate variability after spinal anaesthesia. Br J Anaesth 1993; 71: 523-7.

3 Carpenter RL, Caplan RA, Brown DL, Stephenson C, $W u R$ Incidence and risk factors for side effects of spinal anesthesia. Anesthesiology 1992; 76: 906-16.

4 Clark RB, Thompson DS, Thompson CH. Prevention of spinal hypotension associated with Cesarean section. Anesthesiology 1976; 45: 670-4.

5 Wollman SB, Marx GF. Acute hydration for prevention of hypotension of spinal anesthesia in parturients.

Anesthesiology 1968; 29: 374-80.

\section{Acute tongue swelling in an edentulous patient, relieved by denture insertion}

To the Editor:

We wish to report a 60 -yr-old edentulous woman who had tongue swelling after general anesthesia for a hysterectomy. Extubated 'deep' after surgery, she was able to maintain her airway and breathing. Fifteen minutes later, her tongue was protruding from her mouth, swollen and cyanosed. The swelling rapidly worsened. Fearing impending obstruction, the anesthesiologist decided to examine the airway under sevoflurane anesthesia. As her jaw muscles relaxed, the tongue swelling rapidly subsided and examination was entirely normal but during recovery, swelling recurred. Noting that the alveolar margins were compressing the tongue, causing venous congestion and tongue swelling, the anesthesiologist used his thumbs to separate the margins. Her dentures were fetched from the ward and inserted to maintain this separation. Swelling then did not recur, even though she still had not recovered sufficiently to relax her jaw muscles.

Edentulous patients often have relative macroglossia due to resorption of tooth-bearing bone and a reduced oral cavity volume. ${ }^{1}$ The tongue also spreads laterally when dentures are removed. ${ }^{2}$ This patient also had over-closure of the mandible, further reducing the oral cavity volume. Without her dentures, these changes may have predisposed her to tongue compression and swelling when conscious control of the jaw muscles is lost and masseter hypertory ensues. Denture insertion increased the anterior height of her oral cavity by 24 $\mathrm{mm}$ and the posterior height by $10 \mathrm{~mm}$.

Our patient demonstrates the benefit of denture insertion in the perioperative period - maintenance of 